\title{
Museums of Web design - a look at the past for a contribution to the future
}

With the birth of the World Wide Web in the early nineties of the twentieth century a new artefact arose, the website, an object digital in nature, immaterial, code-based and code-dependent, accessed and experienced through hardware and software with short life spans, which render the website rapidly obsolete and easily replaced. An object nearly always short lived and that when it disappears leaves hardly any trace. This nature poses serious difficulties to the exhibition and preservation of a collection comprised of such artefacts, subject that only recently started to be addressed from a Museology design standpoint. Our research identified only two cases of web-based museums exhibiting artefacts of Web design they are digitalcraft.org and webmuseum.dk. A qualitative research based analysis aimed at observing and describing allowed the identification of issues and possible answers, essential in giving direction towards a future proposal for a Web design museum in the Portuguese context.

web design, museum, web-based exhibition, preservation

\section{Introduction}

The Web as a global communication medium allows access to global audiences opening online museums to new fluxes of information. The different ways of communicating through the Web potentiate the access and distribution of knowledge, which necessarily affect the ways of web-based exhibition. Understanding how web design artefacts are exhibited on the Web and how to take advantage of the communication potential of the medium is essential. Those issues have been addressed differently by digitalcraft. org and webmuseum.dk. Based on empirical research, within the period of May 2011 until December 2013, these museums remain the two only cases in existence affirmation seconded by Engholm's research (2010b: 345) and as such are exemplary of a museology addressing web design artefacts. An analysis from a design perspective towards understanding how these museums were born, their functioning, how the collections were constructed, curated, exhibited and what preservation methods were implemented is paramount in the projection of a future web design museum.

The first case, www.digitalcraft.org, created to exhibit the collection of Web design and digital games derived from the "digitalcraft" section (2000-2003) of the Frankfurt Museum of Applied Art in Germany, went online in 2003 under the Direction of Franziska Nori. On the page "digitalcraft's archive webpages" from the digitalcraft.org website one can read about the specificity of the artefact addressed and the project itself: 
"(...) websites are permanently updated, renewed, completed, redesigned or even taken from the web. Established or even institutionalised strategies to document the resulting processes of change and development do not exist yet. (...) The goal of this project is to show historically subordinated developments of technological as well as conceptual nature within the web design field. The construction of a server-based and fixed web design collection is moreover to be seen as a strategical impulse, as well as a first concrete contribution to a historiography still to be started in this young metier".

This excerpt summarizes two current problematic in Web design museology, first, the transitory aspect of the artefacts and second, the lack of established or institutionalized means of documenting the process that results from change and development. Nevertheless, Digitalcraft addressed these issues and gathered a collection of artefacts from a global scope with the purpose of defining unique artefacts that represent value to designers, academic and researchers.

The collection was created using the method of manual selection as opposed to an automatized selection accomplished trough web crawlers or other automatized ways as is common in web archives like the Wayback machine (Internet archive). Within the scope of the Web design collection, qualitative criteria are used related to the creative aspects of the artefacts. Using an evaluation scale from one to five, an expert team decided if the objects should be admitted to the collection by applying the scale to four criteria: Navigation, Graphic, Animation and Interactivity.

Initially the collection started by a list of commented links, in which each item was presented with the link for the website, a description, the evaluation scale, three screenshots and technical information about formats. In a second stage, according to the curator Franziska Nori (2005), there was the need to do things differently:

"Working with a link based collection would require an enormous effort for maintaining the current collection accessible. The ephemeral character of the web meant that sites were in constant change or even disappeared, making a long-term archive practically impossible.

Consequently, the collection was rearranged in a second phase, following the principle of long term data saving (...).

We contacted the designer / copyright holder asking for the authorisation to collect the site. The holder was asked to provide us the website's data and to fill in a questionnaire. The data was either being mailed to us (via email, CD ROM or FTP access) or we download it using special software. Afterwards, we mirrored the site on our web server and made it accessible by placing a link on the digitalcraft.org site, therefore creating a redundant security copy."

Besides the files of the website, the designer/owner should supply information within the above-mentioned questionnaire explaining the structural plan of the website, sitemap, narrative structure and concept, and that information was integrated as part of the exhibition as can be seen in Figure 1. The form of exhibition consists of screen captures of the artefact (moments frozen in time) and basic contextual information. 


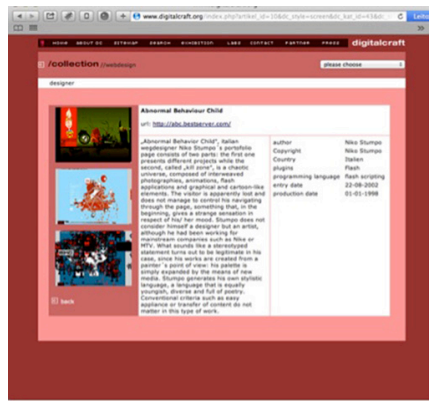

Figure 1.

Screen capture, artefact exhibition, URL: www. digitalcraft.org (in $14 / 01 / 14$ ).

In a third phase the more complex phenomenon of the Web such as online communities were to be addressed. The process was initiated with the archiving of the online community "Internationale Stadt Berlin"' in the museums server. It ended up being the only community in the collection because the museum was then frozen. This happened because as Nori explained via email, there was a change in the Direction of the Frankfurt Museum of Applied Art, the initiator of the project:

"(...) the project has been frozen in the year 2003 due to a change of directorship at the Museum. In agreement with the cultural department of City of Frankfurt who is responsable for the Museum of Applied Arts, I have been able to secore the data at least and to keep it online as reference for future use, but no further development of the collection and research has been done after 2003." (Nori, email in 9/6/2013).

Although the museum was frozen, institutional protocols and partnerships were established in the beginning, along with a team of ten collaborators. A protocol established with the Freiburg University was directed at the creation of an archive of emulators both past and contemporary that included various hardware, browsers, plug-ins and software in order to support the digital preservation of the collection, also partnerships with companies and other institutions for the supply of hardware, software and other technical resources ${ }^{2}$.

Despite the dimension of the Digitalcraft project, anchored in the Frankfurt Museum of Applied Art and the number of collaborators and partnerships, the museum is now still online but frozen in time, almost as a reminder of what could have been.

The second example, www.webmuseum.dk went online in September of 2009 in Beta version (Houstroup: 2009). The researcher and teacher Ida Engholm was the driving force behind the museum witch has an international scope. Engholm presents the museum as follows:

"The academic focus is on the design history development of the web, and through its association with the Danish Museum of Art \& Design, the museum embeds itself in an arts \& crafts context. Thus the museum's purpose is to collect, conserve, and present web material to document web design development." (2010b: 335) 
theme 2

memory

Figure 2.

Screen capture, Homepage and access to the collection through a chronological timeline, URL: www.webmuseum. dk (in 5/3/2013).
Figure 3.

Screen capture, artefact exhibition, URL: www. webmuseum.dk (in 5/3/2013). strand 3

design museums

The museum's mission consists in creating a platform for documenting and communicating the history of the Web, and similarly to Digitalcraft, there was a concern to define criteria for the selection of artefacts:

"Webmuseum.dk features hundreds of websites, each selected with an emphasis on their originality with regard to concept, visual graphic expression, functionality and navigation as well as their representational character in reflecting certain social or cultural approaches to web development (...). The museum is not an archive in the same vein as, say, the international Archive.org, which has broad and representative harvesting criteria but which does not contextualise the material; nor is it a showcase for corporate commercials"

(In Houstrup, 2009).

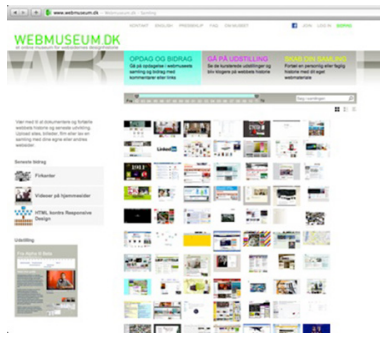

The collection reaches the period from 1992 (although the oldest artefacts date from 1993) to 2012, perceivable by navigating through the thumbnails bellow the navigation timeline in the homepage (Figure 2), however the timeline only allows access to content until 2011, which confuses the user experience and is indicative of lack of updates. The form of exhibition of the artefact consists of screen captures (moments frozen in time) and basic contextual information (Figure 3).

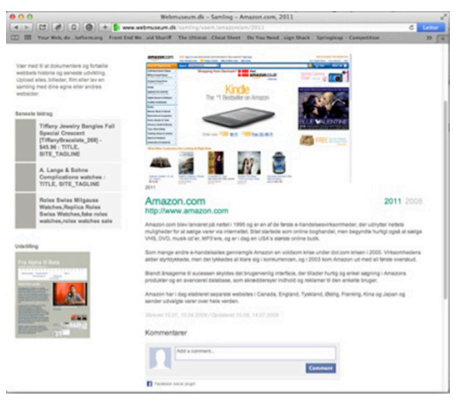

The registered visitor can participate in the section "CREATE YOUR COLLECTION -Tell a personal or professional history with your own web material" (SKAB DIN SAMLING) by creating a personal collection and has the possibility to upload images and videos. Besides this section for participation, the visitor can also comment directly in the individual page of the artefact (Figure 3).

Similarly to Digitalcraft, protocols and partnerships were established with institutions, such as the Design museum Danmark and Danish Centre for design research. 
Both examples show similar strategies in the selection of artefacts, the role of the curator and the need for outside partnerships, although the Webmuseum allows for a participatory model with the public, which doesn't exist in Digitalcraft. The fact that the latter was "frozen" in 2003 and the Web 2.0 started its dissemination in 2004 is probably not a stranger to this reality.

Despite their historical significance, Digitalcraft is "frozen", Webmuseum lacks updating and both are economical in the forms of exhibition and the actual content exhibited. Also they address an international environment when a national scope could go a long way on facilitating the task of managing the collection especially in terms of acquisition. The national scope is in fact, more and more, a pressing concern:

"As the European Community has already declared digital preservation of cultural heritage being of general political interest, it now is the turn of national cultural politics to act, to ensure that not only national libraries but also museums realize these targets." (Nori, 2005)

The previous analysis of the two museums is essential for a future design of a Portuguese Web design museum. Such design lays not only in the graphic and interactive components but contemplates the service design and as such has to address the following challenges:

- Non-existence of a collection of Web design from a museum perspective.

- Immateriality and transitory characteristic of the artefact and of the medium itself, that leads to the loss of the artefact.

- The complexity of digital preservation strategies led by a rapid technological obsolescence.

- The role of the curator that in the Web medium cannot afford to impose its "viewpoint" (Kerchove 1998: 179) and has to act more as a mediator to accommodate the participatory model of the Web.

To address these challenges we propose the following answers:

- The collection can be constructed with the active participation of the designer by answering a questionnaire as part of the museum strategy. Besides submitting the work, accompanied of images and videos of the design process, they give information about the technologies used, name of the participants, briefing, descriptive memory and other contextual information that only the producer of the artefact has knowledge of. In this manner the exhibition of the artefact acquires extra and rich layers of meaning.

- To recover some of artefacts of the past it's necessary an almost digital archaeological stance. The collaboration between the curator and the designer/ owner is essential. Either can be the initiator of the process of recovery. Sometimes the artefact itself can no longer be recovered, but some traces of the artefact can. That is especially relevant for a historic construction. All of these remains (that can include images, videos, interviews, texts, drawings and blueprints) are relevant from a design history and theory perspective once contextualized. A partnership with "Arquivo da Web portuguesa" to recover snapshots of past artefacts could prove relevant and be integrated in the exhibition of the artefact.

- The museum will need digital preservation specialists to address the complex task of long-term saving of the artefacts, which requires also specific hardware and software. If a country hosts a Technology museum the creation of a partnership would be an option 
to help maintain a long-term access to the technologies once they become obsolete. Another option can be similar to the solution encountered by Digitalcraft and their partnership with the Freiburg University.

- The collection developed from a design perspective, should embrace not just the artefact, but also the process of design and the anatomy of use of the objects, so the participation of the designers and the visitors, each with its specific role, is a rich source of information that amplifies the ways in which to experience the artefact. The flow of information thus integrated in the collection needs mediation, function attributed to the curator.

\section{Conclusion}

We presented the problematic behind web museums of web design by looking at the past and defend the need of a museum in a Portuguese scope while suggesting paths for its creation. Despite the foreseeable difficulties of that task, of which Digitalcraft and Webmuseum give strong indication, it nevertheless needs to be undertaken. We've concluded that strong partnerships are necessary and also a variety of human and technological resources to accomplish the different tasks that a web museum presents. The preservation and exhibition of the cultural heritage generated when design meets the Web and that allows multiple voices in the museum still has a long way to go.

\section{References}

Engholm, I. (2002) 'Digital style history: the development of graphic design on the Internet', Digital Creativity, vol. 13, no. 4, pp. 193-212.

Engholm, I. \& Klastrup, L. (2010a) Websites as Artefacts: a New Model for Website Analysis, Available: http://www.re-ad.dk/dcdr/en/publications/websites-asartefacts(db148840-5917-11df-9751-00oea68e967b).html, [Jan 2012].

Engholm, I. (2010b) 'Research-based Online Presentation of Web Design History: The Case of webmuseum.dk' in Brugger, Niels (ed.) Web History, Peter Lang.

Houstrup, I. (2009) 'Webmuseum 2.0', Design Research webzine [Electronic] no. 22 October 2009. Available: http://www.dcdr.dk/uk/Menu/Update/Webzine/Articles/ Webmuseum+2.0 [30 March 2011].

Kerchove, D. (1998) Inteligência conectiva: A emergência da cibersociedade, Lisboa: Fundação para a Divulgação das Tecnologias de Informação.

Nori, F. (?) Management of meanings - annotations on the curatorial work realized by digitalcraft.org. Available: http://www.digitalcraft.org/index.php?artikel_id=552, [12 Dec 2012]. Nori, F. (2005) A Decade of Webdesign. Amsterdam, Available: http://www.digitalcraft. org/index.php?artikel_id=550, [14 Feb 2012].

digitalcraft's archive webpages. Available: http://www.digitalcraft.org/index.php?artikel_ $\mathrm{id}=312 \&$ PHPSESSID=6af210b34229965aa4b6d3caoeg2bfea, [15 Feb 2013].

\section{Acknowledgements}

This work is funded by FEDER through the Operational Competitiveness Programme COMPETE - and by national funds through the Foundation for Science and Technology - FCT - in the scope of project PTDC/CPC-DES/4754/2012 (FCOMP-01-0124FEDER-028530).

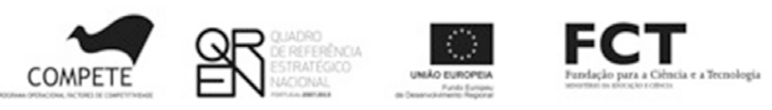

